\title{
Convergence Theorems for Fixed Points of Multivalued Mappings in Hilbert Spaces
}

\author{
N. Djitte and M. Sene \\ Section de Mathématiques Appliquées, Université Gaston Berger, BP 234 Saint Louis, Senegal \\ Correspondence should be addressed to N. Djitte; ngalla.djitte@ugb.edu.sn
}

Received 29 April 2014; Accepted 25 August 2014; Published 24 September 2014

Academic Editor: Remi Léandre

Copyright ( 2014 N. Djitte and M. Sene. This is an open access article distributed under the Creative Commons Attribution License, which permits unrestricted use, distribution, and reproduction in any medium, provided the original work is properly cited.

Let $H$ be a real Hilbert space and $K$ a nonempty closed convex subset of $H$. Suppose $T: K \rightarrow \mathrm{CB}(K)$ is a multivalued Lipschitz pseudocontractive mapping such that $F(T) \neq \emptyset$. An Ishikawa-type iterative algorithm is constructed and it is shown that, for the corresponding sequence $\left\{x_{n}\right\}$, under appropriate conditions on the iteration parameters, $\liminf _{n \rightarrow \infty} d\left(x_{n}, T x_{n}\right)=0$ holds. Finally, convergence theorems are proved under approximate additional conditions. Our theorems are significant improvement on important recent results of Panyanak (2007) and Sastry and Babu (2005).

\section{Introduction}

Let $K$ be a nonempty subset of a normed space $E$. The set $K$ is called proximinal (see, e.g., [1-4]) if for each $x \in E$ there exists $u \in K$ such that

$$
d(x, u)=\inf \{\|x-y\|: y \in K\}=d(x, K),
$$

where $d(x, y)=\|x-y\|$ for all $x, y \in E$. It is known that every nonempty closed convex subset of a real Hilbert space is proximinal. Let $\mathrm{CB}(K)$ and $P(K)$ denote the families of nonempty closed bounded subsets and nonempty proximinal bounded subsets of $K$, respectively. The Hausdorff metric on $\mathrm{CB}(K)$ is defined by

$$
H(A, B)=\max \left\{\sup _{a \in A} d(a, B), \sup _{b \in B} d(b, A)\right\}
$$

for all $A, B \in \mathrm{CB}(K)$. Let $T: D(T) \subseteq E \rightarrow \mathrm{CB}(E)$ be a multivalued mapping on $E$. A point $x \in D(T)$ is called a fixed point of $T$ if and only if $x \in T x$. The set $F(T):=\{x \in D(T)$ : $x \in T x\}$ is called the fixed point set of $T$.

A multivalued mapping $T: D(T) \subseteq E \rightarrow 2^{E}$ is called Lipschitzian if there exists $L>0$ such that

$$
H(T x, T y) \leq L\|x-y\| \quad \forall x, y \in D(T) .
$$

In (3), if $L \in(0,1), T$ is said to be a contraction, and $T$ is called nonexpansive if $L=1$.

Existence theorem for fixed point of multivalued contractions and nonexpansive mappings using the Hausdorff metric have been proved by several authors (see, e.g., Nadler Jr. [5], Markin [6], and Lim [7]). Later, an interesting and rich fixed point theory for such maps and more general maps was developed which has applications in control theory, convex optimization, differential inclusion, and economics (see Gorniewicz [8] and references cited therein).

Several theorems have been proved on the approximation of fixed points of multivalued nonexpansive mappings (see, e.g., $[1-4,9,10]$ and the references therein) and their generalizations (see, e.g., $[11,12]$ ).

Sastry and Babu [2] introduced the following iterative scheme. Let $T: E \rightarrow P(E)$ be a multivalued mapping and let $x^{*}$ be a fixed point of $T$. The sequence of iterates is given for $x_{0} \in E$ by

$$
\begin{gathered}
x_{n+1}=\left(1-\alpha_{n}\right) x_{n}+\alpha_{n} y_{n} \quad \forall n \geq 0, \quad y_{n} \in T x_{n}, \\
\left\|y_{n}-x^{*}\right\|=d\left(T x_{n}, x^{*}\right),
\end{gathered}
$$

where $\alpha_{n}$ is a real sequence in $(0,1)$ satisfying the following conditions:
(i) $\sum_{n=1}^{\infty} \alpha_{n}=\infty$; 
(ii) $\lim \alpha_{n}=0$.

They also introduced the following sequence:

$$
\begin{gathered}
y_{n}=\left(1-\beta_{n}\right) x_{n}+\beta_{n} z_{n}, \quad z_{n} \in T x_{n}, \\
\left\|z_{n}-x^{*}\right\|=d\left(x^{*}, T x_{n}\right), \\
x_{n+1}=\left(1-\alpha_{n}\right) x_{n}+\alpha_{n} u_{n}, \quad u_{n} \in T y_{n}, \\
\left\|u_{n}-x^{*}\right\|=d\left(T y_{n}, x^{*}\right),
\end{gathered}
$$

where $\left\{\alpha_{n}\right\},\left\{\beta_{n}\right\}$ are real sequences satisfying the following conditions:

(i) $0 \leq \alpha_{n}, \beta_{n}<1$;

(ii) $\lim _{n \rightarrow \infty} \beta_{n}=0$;

(iii) $\sum_{n=1}^{\infty} \alpha_{n} \beta_{n}=\infty$.

Sastry and Babu called the process defined by (4) a Mann iteration process and the process defined by (5) where the iteration parameters $\alpha_{n}, \beta_{n}$ satisfy conditions (i), (ii), and (iii) an Ishikawa iteration process. They proved in [2] that the Mann and Ishikawa iteration schemes for a multivalued map $T$ with fixed point $p$ converge to a fixed point of $T$ under certain conditions. More precisely, they proved the following result for a multivalued nonexpansive map with compact domain.

Theorem SB (Sastry and Babu [2]). Let $H$ be real Hilbert space, $K$ a nonempty compact convex subset of $H$, and $T$ : $K \rightarrow P(K)$ a multivalued nonexpansive map with a fixed point p. Assume that (i) $0 \leq \alpha_{n}, \beta_{n}<1$; (ii) $\beta_{n} \rightarrow 0$; and (iii) $\sum \alpha_{n} \beta_{n}=\infty$. Then, the sequence $\left\{x_{n}\right\}$ defined by (5) converges strongly to a fixed point of $T$.

Panyanak [1] extended the above result of Sastry and Babu [2] to uniformly convex real Banach spaces. He proved the following result.

Theorem P1 (Panyanak [1]). Let E be a uniformly convex real Banach space, $K$ a nonempty compact convex subset of $E$, and $T: K \rightarrow P(K)$ a multivalued nonexpansive map with a fixed point $p$. Assume that (i) $0 \leq \alpha_{n}, \beta_{n}<1$; (ii) $\beta_{n} \rightarrow 0$; and (iii) $\sum \alpha_{n} \beta_{n}=\infty$. Then, the sequence $\left\{x_{n}\right\}$ defined by (5) converges strongly to a fixed point of $T$.

Panyanak [1] also modified the iteration schemes of Sastry and Babu [2]. Let $K$ be a nonempty closed convex subset of a real Banach space and let $T: K \rightarrow P(K)$ be a multivalued map with $F(T)$ a nonempty proximinal subset of $K$.

The sequence of Mann iterates is defined by $x_{0} \in K$,

$$
\begin{array}{r}
x_{n+1}=\left(1-\alpha_{n}\right) x_{n}+\alpha_{n} y_{n}, \\
\alpha_{n} \in[a, b], \quad 0<a<b<1, \quad n \geq 0,
\end{array}
$$

where $y_{n} \in T x_{n}$ is such that $\left\|y_{n}-u_{n}\right\|=d\left(u_{n}, T x_{n}\right)$ and $u_{n} \in$ $F(T)$ is such that $\left\|x_{n}-u_{n}\right\|=d\left(x_{n}, F(T)\right)$.

The sequence of Ishikawa iterates is defined by $x_{0} \in K$,

$$
\begin{aligned}
y_{n} & =\left(1-\beta_{n}\right) x_{n}+\beta_{n} z_{n}, \\
\beta_{n} \in[a, b], & 0<a<b<1, \quad n \geq 0,
\end{aligned}
$$

where $z_{n} \in T x_{n}$ is such that $\left\|z_{n}-u_{n}\right\|=d\left(u_{n}, T x_{n}\right)$ and $u_{n} \epsilon$ $F(T)$ is such that $\left\|x_{n}-u_{n}\right\|=d\left(x_{n}, F(T)\right)$. Consider

$$
\begin{array}{r}
x_{n+1}=\left(1-\alpha_{n}\right) x_{n}+\alpha_{n} z_{n}^{\prime}, \\
\alpha_{n} \in[a, b], \quad 0<a<b<1, \quad n \geq 0,
\end{array}
$$

where $z_{n}^{\prime} \in T y_{n}$ is such that $\left\|z_{n}^{\prime}-v_{n}\right\|=d\left(v_{n}, T y_{n}\right)$ and $v_{n} \epsilon$ $F(T)$ is such that $\left\|y_{n}-v_{n}\right\|=d\left(y_{n}, F(T)\right)$. Before we state his theorem, we need the following definition.

A mapping $T: K \rightarrow \mathrm{CB}(K)$ is said to satisfy condition $(I)$ if there exists a strictly increasing function $f:[0, \infty) \rightarrow$ $[0, \infty)$ with $f(0)=0, f(r)>0$ for all $r \in(0, \infty)$ such that

$$
d(x, T(x)) \geq f(d(x, F(T))) \quad \forall x \in D(T) .
$$

Theorem P2 (Panyanak [1]). Let E be a uniformly convex real Banach space, $K$ a nonempty closed bounded convex subset of $E$, and $T: K \rightarrow P(K)$ a multivalued nonexpansive map that satisfies condition (I). Assume that (i) $0 \leq \alpha_{n}<1$ and (ii) $\sum \alpha_{n}=\infty$. Suppose that $F(T)$ is a nonempty proximinal subset of $K$. Then, the sequence $\left\{x_{n}\right\}$ defined by (6) converges strongly to a fixed point of $T$.

Panyanak [1] then asked the following question.

Question (P). Is Theorem P2 true for the Ishikawa iterates defined by (7) and (8)?

As remarked by Nadler Jr. [5], the definition of the Hausdorff metric on $\mathrm{CB}(E)$ gives the following useful result.

Lemma 1. Let $A, B \in C B(X)$ and $a \in A$. For every $\gamma>0$, there exists $b \in B$ such that

$$
d(a, b) \leq H(A, B)+\gamma
$$

Song and Wang [3, 4] modified the iteration process by Panyanak [1] and improved the results therein. They gave their iteration scheme as follows.

Let $K$ be a nonempty closed convex subset of a real Banach space and let $T: K \rightarrow \mathrm{CB}(K)$ be a multivalued map. Let $\alpha_{n}, \beta_{n} \in[0,1]$ and $\gamma_{n} \in(0, \infty)$ be such that $\lim _{n \rightarrow \infty} \gamma_{n}=$ 0 . Choosing $x_{0} \in K$,

$$
\begin{gathered}
y_{n}=\left(1-\beta_{n}\right) x_{n}+\beta_{n} z_{n}, \\
x_{n+1}=\left(1-\alpha_{n}\right) x_{n}+\alpha_{n} u_{n},
\end{gathered}
$$

where $z_{n} \in T x_{n}, u_{n} \in T y_{n}$ are such that

$$
\begin{gathered}
\left\|z_{n}-u_{n}\right\| \leq H\left(T x_{n}, T y_{n}\right)+\gamma_{n}, \\
\left\|z_{n+1}-u_{n}\right\| \leq H\left(T x_{n+1}, T y_{n}\right)+\gamma_{n} .
\end{gathered}
$$

They then proved the following result.

Theorem SW (Song and Wang [3, 4]). Let $K$ be a nonempty compact convex subset of a uniformly convex real Banach space $E$. Let $T: K \rightarrow C B(K)$ be a multivalued nonexpansive mapping with $F(T) \neq \emptyset$ satisfying $T(p)=\{p\}$ for all $p \in$ $F(T)$. Assume that (i) $0 \leq \alpha_{n}, \beta_{n}<1$; (ii) $\beta_{n} \rightarrow 0$; and (iii) $\sum \alpha_{n} \beta_{n}=\infty$. Then, the Ishikawa sequence defined by (11) converges strongly to a fixed point of $T$. 
Shahzad and Zegeye [13] extended and improved the results of Sastry and Babu [2], Panyanak [1], and Son and Wang $[3,4]$ to multivalued quasi-nonexpansive maps. Also, in an attempt to remove the restriction $T p=\{p\} \forall p \in F(T)$ in Theorem SW, they introduced a new iteration scheme as follows.

Let $K$ be a nonempty closed convex subset of a real Banach space, $T: K \rightarrow P(K)$ a multivalued map, and $P_{T} x:=\{y \in T x:\|x-y\|=d(x, T x)\}$. Let $\alpha_{n}, \beta_{n} \in[0,1]$. Choose $x_{0} \in K$, and define $\left\{x_{n}\right\}$ as follows:

$$
\begin{gathered}
y_{n}=\left(1-\beta_{n}\right) x_{n}+\beta_{n} z_{n}, \\
x_{n+1}=\left(1-\alpha_{n}\right) x_{n}+\alpha_{n} u_{n},
\end{gathered}
$$

where $z_{n} \in P_{T} x_{n}, u_{n} \in P_{T} y_{n}$. They then proved the following result.

Theorem SZ (Shahzad and Zegeye [13]). Let X be a uniformly convex real Banach space, $K$ a nonempty convex subset of $X$, and $T: K \rightarrow P(K)$ a multivalued map with $F(T) \neq \emptyset$ such that $P_{T}$ is nonexpansive. Let $\left\{x_{n}\right\}$ be the Ishikawa iterates defined by (13). Assume that $T$ satisfies condition (I) and $\alpha_{n}, \beta_{n} \in[a, b] \subset(0,1)$. Then, $\left\{x_{n}\right\}$ converges strongly to a fixed point of $T$.

Remark 2. In recursion formula (4), the authors take $y_{n} \in$ $T\left(x_{n}\right)$ such that $\left\|y_{n}-x^{*}\right\|=d\left(x^{*}, T x_{n}\right)$. The existence of $y_{n}$ satisfying this condition is guaranteed by the assumption that $T x_{n}$ is proximinal. In general such a $y_{n}$ is extremely difficult to pick. If $T x_{n}$ is proximinal, it is not difficult to prove that it is closed. If, in addition, it is a convex subset of a real Hilbert space, then $y_{n}$ is unique and is characterized by

$$
\left\langle x^{*}-y_{n}, y_{n}-u_{n}\right\rangle \geq 0 \quad \forall u_{n} \in T x_{n} .
$$

One can see from this inequality that it is not easy to pick $y_{n} \in T x_{n}$ satisfying

$$
\left\|y_{n}-x^{*}\right\|=d\left(x^{*}, T x_{n}\right)
$$

at every step of the iteration process. So, recursion formula (4) is not convenient to use in any possible application. Also, the recursion formulas defined in (7) and (8) are not convenient to use in any possible application. The sequences $\left\{z_{n}\right\}$ and $\left\{z_{n}^{\prime}\right\}$ are not known precisely. The restrictions $z_{n} \in T x_{n},\left\|z_{n}-u_{n}\right\|=$ $d\left(u_{n}, T x_{n}\right), u_{n} \in F(T)$, and $z_{n}^{\prime} \in T y_{n},\left\|z_{n}^{\prime}-v_{n}\right\|=d\left(v_{n}, T y_{n}\right)$, $v_{n} \in F(T)$, make them difficult to use. These restrictions on $z_{n}$ and $z_{n}^{\prime}$ depend on $F(T)$, the fixed points set. So, the recursions formulas (7) and (8) are not easily useable.

Definition 3. Let $K$ be a nonempty subset of a real Hilbert space $H$. A map $T: K \rightarrow H$ is called $k$-strictly pseudocontractive if there exists $k \in(0,1)$ such that

$$
\begin{array}{r}
\|T x-T y\|^{2} \leq\|x-y\|^{2}+k\|x-y-(T x-T y)\|^{2} \\
\forall x, y \in K .
\end{array}
$$

If $k=1$ in (16), the map $T$ is said to be pseudocontractive.
Browder and Petryshyn [14] introduced and studied the class of strictly pseudocontractive maps as an important generalization of the class of nonexpansive maps (mappings $T: K \rightarrow K$ satisfying $\|T x-T y\| \leq\|x-y\| \forall x, y \in K)$. It is trivial to see that every nonexpansive map is strictly pseudocontractive.

Motivated by this, Chidume et al. [15] introduced the class of multivalued strictly pseudocontractive maps defined on a real Hilbert space $H$ as follows.

Definition 4. A multivalued map $T: D(T) \subset H \rightarrow 2^{H}$ is called $k$-strictly pseudocontractive if there exists $k \in(0,1)$ such that, for all $x, y \in D(T)$,

$$
\begin{array}{r}
(H(T x, T y))^{2} \leq\|x-y\|^{2}+k\|x-y-(u-v)\|^{2} \\
\forall u \in T x, \quad v \in T y .
\end{array}
$$

If $k=1$ in (17), the map $T$ is said to be pseudocontractive.

We observe from (17) that every nonexpansive mapping is strict pseudocontractive and hence the class of pseudocontractive mappings is a more general class of mappings.

Then, they proved strong convergence theorems for this class of mappings. The recursion formula used is of the Krasnoselskii-type [16].

Theorem CA1 (Chidume et al. [15]). Let $K$ be a nonempty closed convex subset of a real Hilbert space H. Suppose that $T: K \rightarrow C B(K)$ is a multivalued $k$-strictly pseudocontractive mapping such that $F(T) \neq \emptyset$. Assume that $T p=\{p\} \forall p \in$ $F(T)$. Let $\left\{x_{n}\right\}$ be a sequence defined by $x_{0} \in K$,

$$
x_{n+1}=(1-\lambda) x_{n}+\lambda y_{n}, \quad n \geq 0,
$$

where $y_{n} \in T x_{n}$ and $\lambda \in(0,1-k)$. Then, $\lim _{n \rightarrow \infty} d\left(x_{n}, T x_{n}\right)=$ 0 .

Theorem CA2 (Chidume et al. [15]). Let $K$ be a nonempty compact convex subset of a real Hilbert space $H$ and let $T$ : $K \rightarrow C B(K)$ be a multivalued $k$-strictly pseudocontractive mapping with $F(T) \neq \emptyset$ such that $T p=\{p\} \forall p \in F(T)$. Suppose that $T$ is continuous. Let $\left\{x_{n}\right\}$ be a sequence defined by $x_{0} \in K$,

$$
x_{n+1}=(1-\lambda) x_{n}+\lambda y_{n},
$$

where $y_{n} \in T x_{n}$ and $\lambda \in(0,1-k)$. Then, the sequence $\left\{x_{n}\right\}$ converges strongly to a fixed point of $T$.

Remark 5. We note that, for the more general situation of approximating a fixed point of a multivalued Lipschitz pseudocontractive map in a real Hilbert space, an example of Chidume and Mutangadura [17] shows that, even in the single-valued case, the Mann iteration method does not always converge in the setting of Theorem CA2.

We now give an example of multivalued pseudocontractive map (Definition 4) which is not nonexpansive. 
Example 6. Let $T:[0,1]) \rightarrow 2^{\mathbb{R}}$ be the multivalued map defined by

$$
T x= \begin{cases}\{2\} & \text { if } x=0, \\ \{0, x\} & \text { if } x \neq 0 .\end{cases}
$$

(i) $T$ satisfies, for all $x, y \in D(T)$,

$$
\begin{array}{r}
(H(T x, T y))^{2} \leq|x-y|^{2}+|(x-u)-(y-v)|^{2}, \\
\forall u \in T x, \quad v \in T y .
\end{array}
$$

(ii) $T$ is not nonexpansive.

Proof of (i). Inequality (21) is obvious for $x=y=0$. Now for $(x, y) \neq(0,0)$, we proceed as follows.

Case 1. Assume that $x, y \in(0,1]$. In this case, $T x=\{0, x\}$ and $T y=\{0, y\}$. Therefore, we have

$$
\begin{aligned}
H(T x, T y) & =\max \left\{\sup _{a \in T y} d(a,\{0, x\}), \sup _{b \in T x} d(b,\{0, y\})\right\} \\
& =\max \{\min \{x,|x-y|\}, \min \{y,|x-y|\}\} \\
& = \begin{cases}\max \{|x-y|, \min \{y,|x-y|\}\} & \text { if } x \geq y \\
\max \{\min \{x,|x-y|\},|x-y|\} & \text { if } x \leq y\end{cases} \\
& =|x-y| .
\end{aligned}
$$

Hence, for all $x, y \in(0,1]$, we have

$$
\begin{array}{r}
(H(T x, T y))^{2} \leq|x-y|^{2}+|(x-u)-(y-v)|^{2}, \\
\forall u \in T x, \quad v \in T y .
\end{array}
$$

Case 2. Assume that $x \in(0,1]$ and $y=0$. In this case, we have $T x=\{0, x\}$ and $T y=T 0=\{2\}$.

Therefore,

$$
\begin{aligned}
H(T x, T y) & =\max \left\{\sup _{a \in\{2\}} d(a,\{0, x\}), \sup _{b \in\{0, x\}}|2-b|\right\} \\
& =\sup _{b \in\{0, x\}}|2-b| \\
& =\sup \{2,-x+2\} \\
& =2 .
\end{aligned}
$$

On the other hand, let $u \in T x=\{0, x\}$ and $v \in T y=\{2\}$.

(i) If $u=0$, then

$$
|(x-u)-(y-v)|^{2}=(x+2)^{2} \geq(H(T x, T y))^{2} .
$$

(ii) If $u=x$, we have

$$
|(x-u)-(y-v)|^{2}=4=(H(T x, T y))^{2} .
$$

Therefore,

$$
\begin{array}{r}
(H(T x, T y))^{2} \leq|x-y|^{2}+|(x-u)-(y-v)|^{2}, \\
\forall u \in T x, \quad v \in T y .
\end{array}
$$

This completes the proof of (i).
Proof of (ii). If $x \in(0,1]$ and $y=0$, we have that $H(T x, T y)=$ 2 and $|x-y|=x$. So,

$$
H(T x, T y)>|x-y| .
$$

This proves that $T$ is not nonexpansive.

It is our purpose in this paper to prove strong convergence theorems for the class of multivalued Lipschitz pseudocontractive maps in real Hilbert spaces. We use the recursion formula (11), dispensing with the second restriction on the sequences $\left\{z_{n}\right\}$ and $\left\{u_{n}\right\}:\left\|z_{n+1}-u_{n-1}\right\| \leq H\left(T x_{n+1}, T y_{n}\right)+\gamma_{n}, n \geq 1$. This class of maps is much more larger than that of multivalued nonexpansive maps used in Theorem SW. So, in the setting of real Hilbert spaces, our theorem improves and extends the result of Song and Wang $[3,4]$.

\section{Preliminaries}

In the sequel, we will need the following results.

Lemma 7 (Daffer and Kaneko [12]). Let $\left\{a_{n}\right\}$ and $\left\{\gamma_{n}\right\}$ be sequences of nonnegative real numbers satisfying the following relation:

$$
a_{n+1} \leq a_{n}+\gamma_{n} \quad \forall n \geq n_{0},
$$

where $n_{0}$ is a nonnegative integer. If $\sum \gamma_{n}<\infty$, then $\lim _{n \rightarrow \infty} a_{n}$ exists.

Lemma 8. Let $H$ be a real Hilbert space. Then

$$
\|\lambda x+(1-\lambda) y\|^{2}=\lambda\|x\|^{2}+(1-\lambda)\|y\|^{2}-\lambda(1-\lambda)\|x-y\|^{2}
$$

for all $x, y \in H$, and $\lambda \in[0,1]$.

\section{Main Results}

We use the following iteration scheme.

Let $K$ be a nonempty closed convex subset of a real Hilbert space $H$ and $\alpha_{n}, \beta_{n}$, and $\gamma_{n}$ real sequences in $(0,1]$. Let $\left\{x_{n}\right\}$ be the sequence defined from arbitrary $x_{1} \in K$ by

$$
\begin{gathered}
y_{n}=\left(1-\beta_{n}\right) x_{n}+\beta_{n} u_{n}, \quad n \geq 1, \\
x_{n+1}=\left(1-\alpha_{n}\right) x_{n}+\alpha_{n} w_{n}, \quad n \geq 1,
\end{gathered}
$$

where $u_{n} \in T x_{n}, w_{n} \in T y_{n}$ are such that

$$
\left\|u_{n}-w_{n}\right\| \leq H\left(T x_{n}, T y_{n}\right)+\gamma_{n} .
$$

We first prove the following theorem.

Theorem 9. Let $K$ be a nonempty closed convex subset of a real Hilbert space $H$ and $T: K \rightarrow C B(K)$ a multivalued L-Lipschitz pseudocontractive mapping with $F(T) \neq \emptyset$ and $T p=\{p\} \forall p \in F(T)$. Let $\left\{x_{n}\right\}$ be the sequence defined by (31) and (32). Assume that (i) $0 \leq \alpha_{n} \leq \beta_{n}<1 \forall n \geq 0$; (ii) $\lim \beta_{n}=0$; (iii) $\sum \alpha_{n} \beta_{n}=\infty$ and $\sum \gamma_{n}^{2}<\infty$. Then, $\liminf _{n \rightarrow \infty} d\left(x_{n}, T x_{n}\right)=0$. 
Proof. Let $p \in F(T)$. Using Lemma 8, the fact that $T$ is pseudocontractive, and the assumption $T p=\{p\} \forall p \in F(T)$, we have

$$
\begin{aligned}
\| x_{n+1} & -p \|^{2} \\
= & \left(1-\alpha_{n}\right)\left\|x_{n}-p\right\|^{2}+\alpha_{n}\left\|w_{n}-p\right\|^{2} \\
& -\alpha_{n}\left(1-\alpha_{n}\right)\left\|x_{n}-w_{n}\right\|^{2} \\
\leq & \left(1-\alpha_{n}\right)\left\|x_{n}-p\right\|^{2}+\alpha_{n}\left(H\left(T y_{n}, T p\right)\right)^{2} \\
& -\alpha_{n}\left(1-\alpha_{n}\right)\left\|x_{n}-w_{n}\right\|^{2} \\
\leq & \left(1-\alpha_{n}\right)\left\|x_{n}-p\right\|^{2}+\alpha_{n}\left(\left\|y_{n}-p\right\|^{2}+\left\|y_{n}-w_{n}\right\|^{2}\right) \\
& -\alpha_{n}\left(1-\alpha_{n}\right)\left\|x_{n}-w_{n}\right\|^{2} \\
= & \left(1-\alpha_{n}\right)\left\|x_{n}-p\right\|^{2}+\alpha_{n}\left\|y_{n}-p\right\|^{2}+\alpha_{n}\left\|y_{n}-w_{n}\right\|^{2} \\
& -\alpha_{n}\left(1-\alpha_{n}\right)\left\|x_{n}-w_{n}\right\|^{2} .
\end{aligned}
$$

Observing that

$$
\begin{aligned}
\left\|y_{n}-w_{n}\right\|^{2}= & \left(1-\beta_{n}\right)\left\|x_{n}-w_{n}\right\|^{2}+\beta_{n}\left\|u_{n}-w_{n}\right\|^{2} \\
& -\beta_{n}\left(1-\beta_{n}\right)\left\|x_{n}-u_{n}\right\|^{2}
\end{aligned}
$$

then, from inequality (33) and identity (34), we have that

$$
\begin{aligned}
\left\|x_{n+1}-p\right\|^{2} \leq & \left(1-\alpha_{n}\right)\left\|x_{n}-p\right\|^{2}+\alpha_{n}\left\|y_{n}-p\right\|^{2} \\
& +\alpha_{n}\left(\left(1-\beta_{n}\right)\left\|x_{n}-w_{n}\right\|^{2}+\beta_{n}\left\|u_{n}-w_{n}\right\|^{2}\right. \\
& \left.-\beta_{n}\left(1-\beta_{n}\right)\left\|x_{n}-u_{n}\right\|^{2}\right) \\
& -\alpha_{n}\left(1-\alpha_{n}\right)\left\|x_{n}-w_{n}\right\|^{2} .
\end{aligned}
$$

Using again Lemma 8 , the fact that $T$ is pseudocontractive, and the assumption $T p=\{p\} \forall p \in F(T)$, we obtain the following estimates:

$$
\begin{aligned}
\| y_{n}- & p \|^{2} \\
= & \left(1-\beta_{n}\right)\left\|x_{n}-p\right\|^{2}+\beta_{n}\left\|u_{n}-p\right\|^{2} \\
& -\beta_{n}\left(1-\beta_{n}\right)\left\|x_{n}-u_{n}\right\|^{2} \\
\leq & \left(1-\beta_{n}\right)\left\|x_{n}-p\right\|^{2}+\beta_{n}\left(H\left(T x_{n}, T p\right)\right)^{2} \\
& -\beta_{n}\left(1-\beta_{n}\right)\left\|x_{n}-u_{n}\right\|^{2} \\
\leq & \left(1-\beta_{n}\right)\left\|x_{n}-p\right\|^{2}+\beta_{n}\left(\left\|x_{n}-p\right\|^{2}+\left\|u_{n}-x_{n}\right\|^{2}\right) \\
& -\beta_{n}\left(1-\beta_{n}\right)\left\|x_{n}-u_{n}\right\|^{2} \\
= & \left\|x_{n}-p\right\|^{2}+\beta_{n}^{2}\left\|x_{n}-u_{n}\right\|^{2} .
\end{aligned}
$$

Therefore, inequalities (35) and (36) and condition (i) imply that

$$
\begin{aligned}
\left\|x_{n+1}-p\right\|^{2} & \\
\leq & \left(1-\alpha_{n}\right)\left\|x_{n}-p\right\|^{2}+\alpha_{n}\left(\left\|x_{n}-p\right\|^{2}+\beta_{n}^{2}\left\|x_{n}-u_{n}\right\|^{2}\right) \\
& +\alpha_{n}\left(\left(1-\beta_{n}\right)\left\|x_{n}-w_{n}\right\|^{2}+\beta_{n}\left\|u_{n}-w_{n}\right\|^{2}\right. \\
& \left.-\beta_{n}\left(1-\beta_{n}\right)\left\|x_{n}-u_{n}\right\|^{2}\right) \\
& -\alpha_{n}\left(1-\alpha_{n}\right)\left\|x_{n}-w_{n}\right\|^{2} \\
\leq & \left\|x_{n}-p\right\|^{2}+\alpha_{n} \beta_{n}^{2}\left\|x_{n}-u_{n}\right\|^{2}+\alpha_{n}\left(1-\beta_{n}\right)\left\|x_{n}-w_{n}\right\|^{2} \\
& +\alpha_{n} \beta_{n}\left\|u_{n}-w_{n}\right\|^{2}-\alpha_{n} \beta_{n}\left(1-\beta_{n}\right)\left\|x_{n}-u_{n}\right\|^{2} \\
& -\alpha_{n}\left(1-\alpha_{n}\right)\left\|x_{n}-w_{n}\right\|^{2} \\
= & \left\|x_{n}-p\right\|^{2}-\alpha_{n} \beta_{n}\left(1-2 \beta_{n}\right)\left\|x_{n}-u_{n}\right\|^{2} \\
& -\alpha_{n}\left(\beta_{n}-\alpha_{n}\right)\left\|x_{n}-w_{n}\right\|^{2}+\alpha_{n} \beta_{n}\left\|u_{n}-w_{n}\right\|^{2} \\
\leq & \left\|x_{n}-p\right\|^{2}-\alpha_{n} \beta_{n}\left(1-2 \beta_{n}\right)\left\|x_{n}-u_{n}\right\|^{2} \\
& +\alpha_{n} \beta_{n}\left\|u_{n}-w_{n}\right\|^{2} .
\end{aligned}
$$

Using inequality (32), the fact that $T$ is $L$-Lipschitzian, and the recursion formula (31), we have

$$
\left\|u_{n}-w_{n}\right\|^{2} \leq 2 \beta_{n}^{2} L^{2}\left\|x_{n}-u_{n}\right\|^{2}+2 \gamma_{n}^{2} .
$$

Therefore, from inequalities (37) and (38), we obtain

$$
\begin{aligned}
\left\|x_{n+1}-p\right\|^{2} \leq & \left\|x_{n}-p\right\|^{2}-\alpha_{n} \beta_{n}\left(1-2 \beta_{n}-2 L^{2} \beta_{n}^{2}\right) \\
& \times\left\|x_{n}-u_{n}\right\|^{2}+2 \gamma_{n}^{2} .
\end{aligned}
$$

Observing that condition (ii) yields that $\beta_{n}+L^{2} \beta_{n}^{2} \leq 1 / 4$, for all $n \geq N$ for some $N$, it then follows that

$$
\frac{1}{2} \sum_{n=N}^{\infty} \alpha_{n} \beta_{n}\left\|x_{n}-u_{n}\right\|^{2} \leq\left\|x_{N}-p\right\|^{2}+2 \sum_{n=N}^{\infty} \gamma_{n}^{2}<\infty,
$$

which implies, by condition (iii), that $\liminf _{n \rightarrow \infty}\left\|x_{n}-u_{n}\right\|=$ 0 . Since $u_{n} \in T x_{n}$, it follows that $d\left(x_{n}, T x_{n}\right) \leq\left\|x_{n}-u_{n}\right\|$. Therefore, $\liminf _{n \rightarrow \infty} d\left(x_{n}, T x_{n}\right)=0$.

We now prove the following corollaries of Theorem 9.
Corollary 10. Let $K$ be a nonempty closed convex subset of
a real Hilbert space $H$ and $T: K \rightarrow C B(K)$ a multivalued
Lipschitz pseudocontractive mapping with $F(T) \neq \emptyset$ and Tp $=$
$\{p\} \forall p \in F(T)$. Let $\left\{x_{n}\right\}$ be the sequence defined by (31) and
(32). Assume that $T$ is hemicompact, and (i) $0 \leq \alpha_{n} \leq \beta_{n}<$
$1 \forall n \geq 0 ;$ (ii) $\lim \beta_{n}=0$; (iii) $\sum \alpha_{n} \beta_{n}=\infty$; and (iv) $\sum \gamma_{n}^{2}<$
$\infty$. Then, $\left\{x_{n}\right\}$ converges strongly to a fixed point of T.
Corollary 10. Let $K$ be a nonempty closed convex subset of
a real Hilbert space $H$ and $T: K \rightarrow C B(K)$ a multivalued
Lipschitzpseudocontractive mapping with $F(T) \neq \emptyset$ and $T p=$
$\{p\} \forall p \in F(T)$. Let $\left\{x_{n}\right\}$ be the sequence defined by (31) and
(32). Assume that $T$ is hemicompact, and (i) $0 \leq \alpha_{n} \leq \beta_{n}<$
$1 \forall n \geq 0$; (ii) $\lim \beta_{n}=0$; (iii) $\sum \alpha_{n} \beta_{n}=\infty$; and (iv) $\sum \gamma_{n}^{2}<$
$\infty$. Then, $\left\{x_{n}\right\}$ converges strongly to a fixed point of $T$.
Corollary 10. Let $K$ be a nonempty closed convex subset of
a real Hilbert space $H$ and $T: K \rightarrow C B(K)$ a multivalued
Lipschitz pseudocontractive mapping with $F(T) \neq \emptyset$ and $T p=$
$\{p\} \forall p \in F(T)$. Let $\left\{x_{n}\right\}$ be the sequence defined by (31) and
(32). Assume that $T$ is hemicompact, and (i) $0 \leq \alpha_{n} \leq \beta_{n}<$
$1 \forall n \geq 0 ;\left(\right.$ ii) $\lim \beta_{n}=0$; (iii) $\sum \alpha_{n} \beta_{n}=\infty$; and (iv) $\sum \gamma_{n}^{2}<$
$\infty$. Then, $\left\{x_{n}\right\}$ converges strongly to a fixed point of $T$.
Corollary 10. Let $K$ be a nonempty closed convex subset of
a real Hilbert space $H$ and $T: K \rightarrow C B(K)$ a multivalued
Lipschitz pseudocontractive mapping with $F(T) \neq \emptyset$ and $T p=$
$\{p\} \forall p \in F(T)$. Let $\left\{x_{n}\right\}$ be the sequence defined by (31) and
(32). Assume that $T$ is hemicompact, and (i) $0 \leq \alpha_{n} \leq \beta_{n}<$
$1 \forall n \geq 0 ;$ (ii) $\lim \beta_{n}=0$; (iii) $\sum \alpha_{n} \beta_{n}=\infty$; and (iv) $\sum \gamma_{n}^{2}<$
$\infty$. Then, $\left\{x_{n}\right\}$ converges strongly to a fixed point of $T$.
Corollary 10. Let $K$ be a nonempty closed convex subset of
a real Hilbert space $H$ and $T: K \rightarrow C B(K)$ a multivalued
Lipschitz pseudocontractive mapping with $F(T) \neq \emptyset$ and $T p=$
$\{p\} \forall p \in F(T)$. Let $\left\{x_{n}\right\}$ be the sequence defined by (31) and
(32). Assume that $T$ is hemicompact, and (i) $0 \leq \alpha_{n} \leq \beta_{n}<$
$1 \forall n \geq 0 ;\left(\right.$ ii) $\lim \beta_{n}=0$; (iii) $\sum \alpha_{n} \beta_{n}=\infty$; and (iv) $\sum \gamma_{n}^{2}<$
$\infty$. Then, $\left\{x_{n}\right\}$ converges strongly to a fixed point of $T$.
Corollary 10. Let $K$ be a nonempty closed convex subset of
a real Hilbert space $H$ and $T: K \rightarrow C B(K)$ a multivalued
Lipschitz pseudocontractive mapping with $F(T) \neq \emptyset$ and $T p=$
$\{p\} \forall p \in F(T)$. Let $\left\{x_{n}\right\}$ be the sequence defined by (31) and
(32). Assume that $T$ is hemicompact, and (i) $0 \leq \alpha_{n} \leq \beta_{n}<$
$1 \forall n \geq 0 ;\left(\right.$ ii) $\lim \beta_{n}=0$; (iii) $\sum \alpha_{n} \beta_{n}=\infty$; and (iv) $\sum \gamma_{n}^{2}<$
$\infty$. Then, $\left\{x_{n}\right\}$ converges strongly to a fixed point of $T$.
Corollary 10. Let $K$ be a nonempty closed convex subset of
a real Hilbert space $H$ and $T: K \rightarrow C B(K)$ a multivalued
Lipschitz pseudocontractive mapping with $F(T) \neq \emptyset$ and $T p=$
$\{p\} \forall p \in F(T)$. Let $\left\{x_{n}\right\}$ be the sequence defined by (31) and
(32). Assume that $T$ is hemicompact, and (i) $0 \leq \alpha_{n} \leq \beta_{n}<$
$1 \forall n \geq 0$; (ii) $\lim \beta_{n}=0$; (iii) $\sum \alpha_{n} \beta_{n}=\infty$; and (iv) $\sum \gamma_{n}^{2}<$
$\infty$. Then, $\left\{x_{n}\right\}$ converges strongly to a fixed point of $T$. 
Proof. From Theorem 9, we have that $\liminf _{n \rightarrow \infty} d\left(x_{n}\right.$, $\left.T x_{n}\right)=0$. So there exists a subsequence $\left\{x_{n_{k}}\right\}$ of $\left\{x_{n}\right\}$ such that $\lim _{k \rightarrow \infty} d\left(x_{n_{k}}, T x_{n_{k}}\right)=0$. Using the fact that $T$ is hemicompact, the sequence $\left\{x_{n_{k}}\right\}$ has a subsequence denoted again by $\left\{x_{n_{k}}\right\}$ that converges strongly to some $q \in K$. Since $T$ is continuous, we have $d\left(x_{n_{k}}, T x_{n_{k}}\right) \rightarrow d(q, T q)$. Therefore, $d(q, T q)=0$ and so $q \in F(T)$. Now setting $p=q$ in inequality (39) and using condition (ii) we have that

$$
\left\|x_{n+1}-q\right\|^{2} \leq\left\|x_{n}-q\right\|^{2}+2 \gamma_{n}^{2}
$$

for all $n \geq N$ for some $N \geq 1$. Therefore, Lemma 7 implies that $\lim _{n \rightarrow \infty}\left\|x_{n}-q\right\|$ exists. Since $\lim _{k \rightarrow \infty}\left\|x_{n_{k}}-q\right\|=0$, it then follows that $\left\{x_{n}\right\}$ converges strongly to $q \in F(T)$, completing the proof.

We can easily observe that if $T$ is nonexpansive, then it is Lipschitzian and pseudocontractive. Therefore, the following corollary generalizes Theorem SW of Song and Wang $[3,4]$ in the setting of Hilbert spaces.

Corollary 11. Let $K$ be a nonempty compact convex subset of a real Hilbert space $H$ and $T: K \rightarrow C B(K)$ a multivalued Lipschitz pseudocontractive mapping with $F(T) \neq \emptyset$ and $T p=$ $\{p\} \forall p \in F(T)$. Let $\left\{x_{n}\right\}$ be the sequence defined by (31) and (32). Assume that (i) $0 \leq \alpha_{n} \leq \beta_{n}<1 \forall n \geq 0$; (ii) $\lim \beta_{n}=0$; (iii) $\sum \alpha_{n} \beta_{n}=\infty$ and $\sum \gamma_{n}^{2}<\infty$. Then, $\left\{x_{n}\right\}$ converges strongly to a fixed point of $T$.

Proof. Since $K$ is compact, it follows that $T$ is hemicompact. So, the proof follows from Corollary 10.

Corollary 12. Let $K$ be a nonempty closed convex subset of a real Hilbert space $H$, and let $T: K \rightarrow C B(K)$ be a multivalued Lipschitz pseudocontractive mapping with $F(T) \neq \emptyset$ and $T p=$ $\{p\} \forall p \in F(T)$. Let $\left\{x_{n}\right\}$ be the sequence defined by (31) and (32). Assume that $T$ satisfies condition (I) and (i) $0 \leq \alpha_{n} \leq$ $\beta_{n}<1 \forall n \geq 0$; (ii) $\lim \beta_{n}=0$; (iii) $\sum \alpha_{n} \beta_{n}=\infty$; and (iv) $\sum \gamma_{n}^{2}<\infty$. Then, $\left\{x_{n}\right\}$ converges strongly to a fixed point of $T$.

Proof. From Theorem 9, we have that $\liminf _{n \rightarrow \infty} d\left(x_{n}\right.$, $\left.T x_{n}\right)=0$. So there exists a subsequence $\left\{x_{n_{k}}\right\}$ of $\left\{x_{n}\right\}$ such that $\lim _{k \rightarrow \infty} d\left(x_{n_{k}}, T x_{n_{k}}\right)=0$. Since $T$ satisfies condition (I), we have $\lim _{k \rightarrow \infty} d\left(x_{n_{k}}, F(T)\right)=0$. Thus there exist a subsequence of $\left\{x_{n_{k}}\right\}$ denoted again by $\left\{x_{n_{k}}\right\}$ and a sequence $\left\{p_{k}\right\} \subset F(T)$ such that

$$
\left\|x_{n_{k}}-p_{k}\right\| \leq \frac{1}{2^{k}} \quad \forall k
$$

By setting $p=p_{k}$ in inequality (39) and using the condition (ii), we have

$$
\begin{aligned}
\left\|x_{n_{k+1}}-p_{k}\right\|^{2} & \leq\left\|x_{n_{k}}-p_{k}\right\|^{2}+2 \gamma_{n_{k}}^{2} \\
& \leq \frac{1}{2^{k}}+2 \gamma_{n_{k}}^{2}
\end{aligned}
$$

for all $k \geq k_{0}$, for some $k_{0} \geq 1$.
We now show that $\left\{p_{k}\right\}$ is a Cauchy sequence in $K$. Notice that, for $k \geq k_{0}$,

$$
\begin{aligned}
\left\|p_{k+1}-p_{k}\right\|^{2} & \leq 2\left\|p_{k+1}-x_{n_{k+1}}\right\|^{2}+2\left\|x_{n_{k+1}}-p_{k}\right\|^{2} \\
& \leq 2\left(\frac{1}{2^{2 k+2}}+\frac{1}{2^{k}}+2 \gamma_{n_{k}}^{2}\right) \\
& \leq 2\left(\frac{1}{2^{k-1}}+2 \gamma_{n_{k}}^{2}\right) .
\end{aligned}
$$

From condition (iv), it follows that $\left\{p_{k}\right\}$ is a Cauchy sequence in $K$ and thus converges strongly to some $q \in K$. Using the fact that $T$ is $L$-Lipschitzian and $p_{k} \rightarrow q$, we have

$$
d\left(p_{k}, T q\right) \leq H\left(T p_{k}, T q\right) \leq L\left\|p_{k}-q\right\|,
$$

so that $d(q, T q)=0$ and thus $q \in T q$. Therefore, $q \in F(T)$ and $\left\{x_{n_{k}}\right\}$ converges strongly to $q$. Now setting $p=q$ in inequality (39) and using condition (ii) we have that

$$
\left\|x_{n+1}-q\right\|^{2} \leq\left\|x_{n}-q\right\|^{2}+2 \gamma_{n}^{2},
$$

for all $n \geq N$ for some $N \geq 1$. Therefore, Lemma 7 implies that $\lim _{n \rightarrow \infty}\left\|x_{n}-q\right\|$ exists. Since $\lim _{k \rightarrow \infty}\left\|x_{n_{k}}-q\right\|=0$, it then follows that $\left\{x_{n}\right\}$ converges strongly to $q \in F(T)$, completing the proof.

Remark 13. Our theorem and corollaries improve convergence theorems for multivalued nonexpansive mappings in $[1-4,12,13]$ in the following sense.

(i) In our algorithm, $u_{n} \in T x_{n}, w_{n} \in T y_{n}$ do not have to satisfy the restrictive conditions $\left\|u_{n}-x^{*}\right\|=d\left(x^{*}, T x_{n}\right)$ and $\left\|w_{n}-x^{*}\right\|=d\left(x^{*}, T y_{n}\right)$ in the recursion formula (5) and similar restrictions in the recursion formulas (7) and (8). These restrictions on $u_{n}$ and $w_{n}$ depend on $x^{*}$, a fixed point that is being approximated or the fixed points set $F(T)$. Also, in our algorithm, the second restriction on the sequences $\left\{z_{n}\right\}$ and $\left\{u_{n}\right\}:\left\|z_{n+1}-u_{n-1}\right\| \leq H\left(T x_{n+1}, T y_{n}\right)+\gamma_{n}, n \geq 1$, in the recursion formula (11), is removed.

(ii) Our theorem and corollaries are proved for the class of multivalued Lipschitz pseudocontractive mappings which is much more general than that of multivalued nonexpansive mappings

Remark 14. Corollary 11 is an extension of the Theorem of Ishikawa [18] from single-valued to multivalued Lipschitz pseudocontractive mappings.

Remark 15. Real sequences that satisfy the hypotheses of Theorems 9 are $\alpha_{n}=(n+1)^{-1 / 2}, \beta_{n}=(n+1)^{-1 / 2}$, and $\gamma_{n}=(n+1)^{-1}, n \geq 0$.

\section{Conflict of Interests}

The authors declare that there is no conflict of interests regarding the publication of this paper.

\section{Acknowledgment}

This paper is dedicated to the memory of Professor Galaye DIA (1941-2013). The authors thank the referee for his work 
and his valuable suggestion that helped to improve the presentation of this paper.

\section{References}

[1] B. Panyanak, "Mann and Ishikawa iterative processes for multivalued mappings in Banach spaces," Computers and Mathematics with Applications, vol. 54, no. 6, pp. 872-877, 2007.

[2] K. P. R. Sastry and G. V. R. Babu, "Convergence of ishikawa iterates for a multi-valued mapping with a fixed point," Czechoslovak Mathematical Journal, vol. 55, no. 4, pp. 817-826, 2005.

[3] Y. Song and H. Wang, "Mann and Ishikawa iterative processes for multi-valued mappings in Banach Spaces," Computers \& Mathematics with Applications, vol. 54, pp. 872-877, 2007.

[4] Y. Song and H. Wang, "Erratum to "Mann and Ishikawa iterative processes for multi-valued mappings in Banach spaces"', Computers \& Mathematics with Applications, vol. 55, pp. 2999-3002, 2008.

[5] S. B. Nadler Jr., "Multivaled contraction mappings," Pacific Journal of Mathematics, vol. 30, pp. 475-488, 1969.

[6] J. T. Markin, "Continuous dependence of fixed point sets," Proceedings of the American Mathematical Society, vol. 38, pp. 545-547, 1973.

[7] T. C. Lim, "A fixed point theorem for multi-valued nonexpansive mappings in a uniformly convex Banach space," Bulletin of the American Mathematical Society, vol. 80, pp. 1123-1126, 1974.

[8] L. Gorniewicz, Topological Fixed Point Theory of Multivalued Mappings, Kluwer Academic Publishers, Dordrecht, The Netherlands, 1999.

[9] M. Abbas, S. H. Khan, A. R. Khan, and R. P. Agarwal, "Common fixed points of two multivalued nonexpansive mappings by onestep iterative scheme," Applied Mathematics Letters, vol. 24, no. 2, pp. 97-102, 2011.

[10] S. H. Khan, I. Yildirim, and B. E. Rhoades, "A one-step iterative process for two multivalued nonexpansive mappings in Banach spaces," Computers and Mathematics with Applications, vol. 61, no. 10, pp. 3172-3178, 2011.

[11] J. García-Falset, E. Llorens-Fuster, and T. Suzuki, "Fixed point theory for a class of generalized nonexpansive mappings," Journal of Mathematical Analysis and Applications, vol. 375, no. 1, pp. 185-195, 2011.

[12] P. Z. Daffer and H. Kaneko, "Fixed points of generalized contractive multi-valued mappings," Journal of Mathematical Analysis and Applications, vol. 192, no. 2, pp. 655-666, 1995.

[13] N. Shahzad and H. Zegeye, "On Mann and Ishikawa iteration schemes for multi-valued maps in Banach spaces," Nonlinear Analysis, Theory, Methods and Applications, vol. 71, no. 3-4, pp. 838-844, 2009.

[14] F. E. Browder and W. V. Petryshyn, "Construction of fixed points of nonlinear mappings in Hilbert space," Journal of Mathematical Analysis and Applications, vol. 20, no. 2, pp. 197228, 1967.

[15] C. E. Chidume, C. O. Chidume, N. Djitté, and M. S. Minjibir, "Convergence theorems for fixed points of multivalued strictly pseudocontractive mappings in Hilbert spaces," Abstract and Applied Analysis, vol. 2013, Article ID 629468, 10 pages, 2013.

[16] M. A. Krasnosel'ski, "Two observations about the method of successive approximations," Uspehi Matematieskih Nauk, vol. 10, pp. 123-127, 1955.

[17] C. E. Chidume and S. A. Mutangadura, "An example on the mann iteration method for lipschitz pseudocontractions,"
Proceedings of the American Mathematical Society, vol. 129, no. 8, pp. 2359-2363, 2001.

[18] S. Ishikawa, "Fixed points by a new iteration method," Proceedings of the American Mathematical Society, vol. 44, pp. 147-150, 1974. 


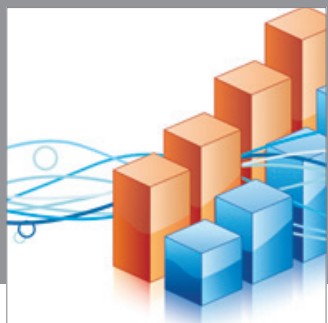

Advances in

Operations Research

mansans

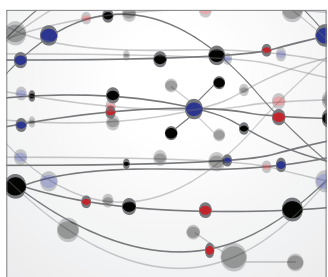

The Scientific World Journal
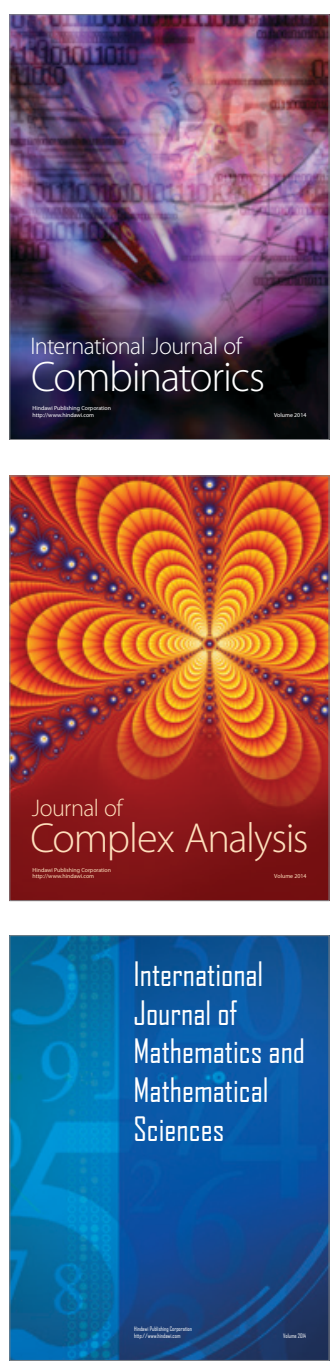
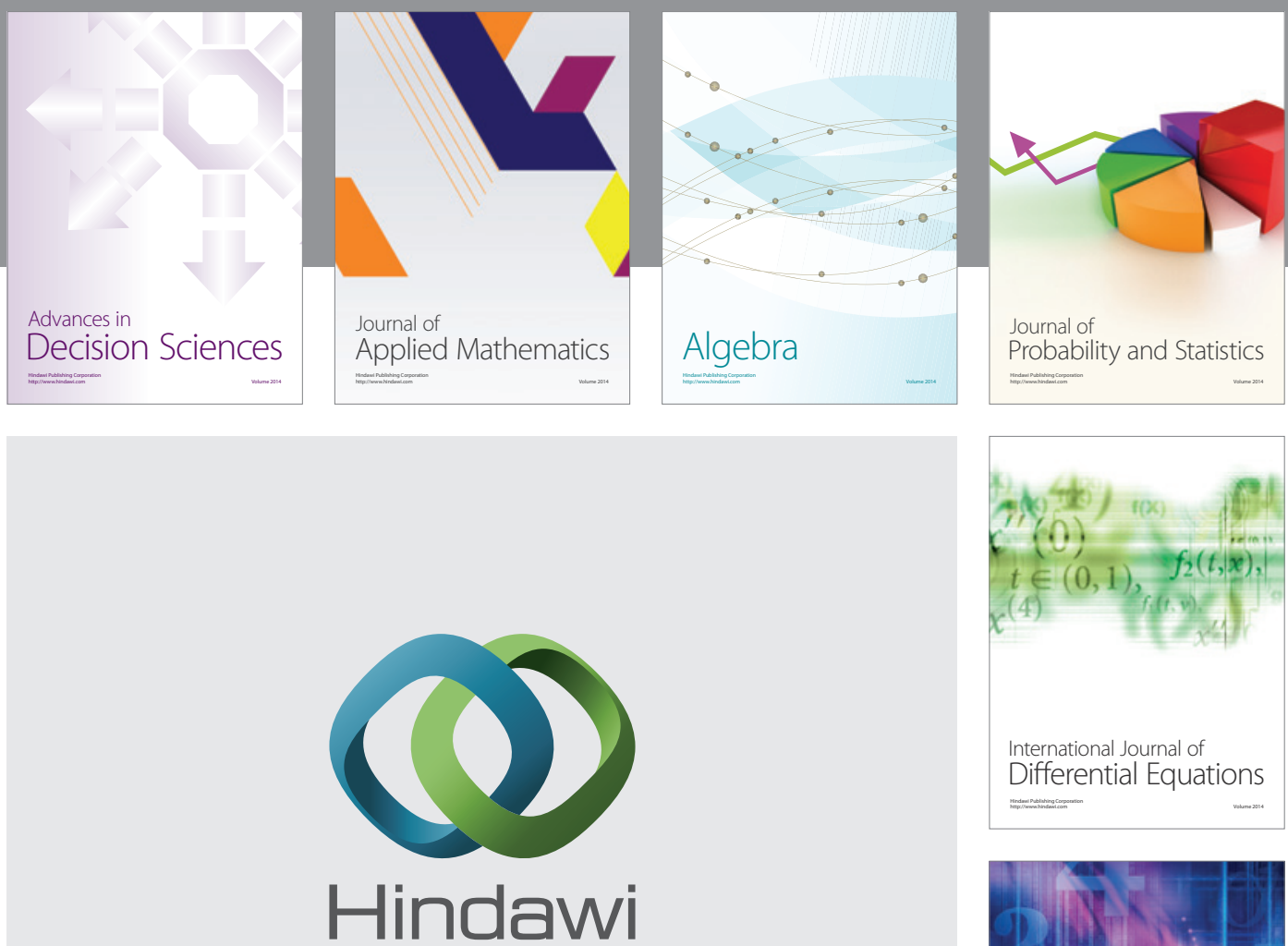

Submit your manuscripts at http://www.hindawi.com
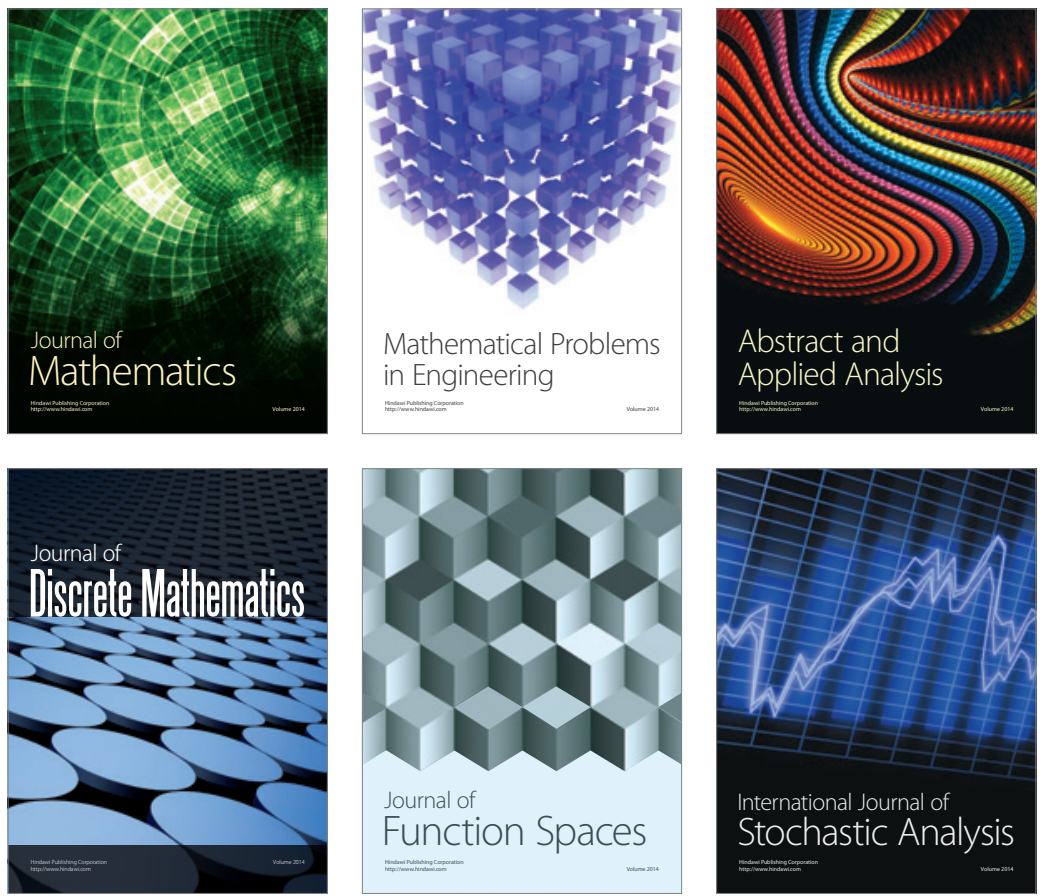

Journal of

Function Spaces

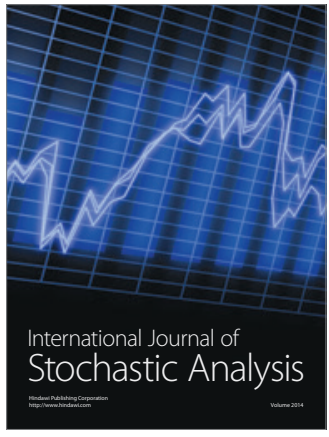

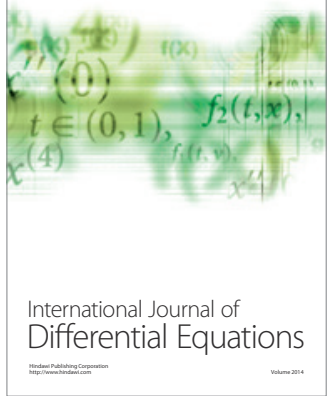
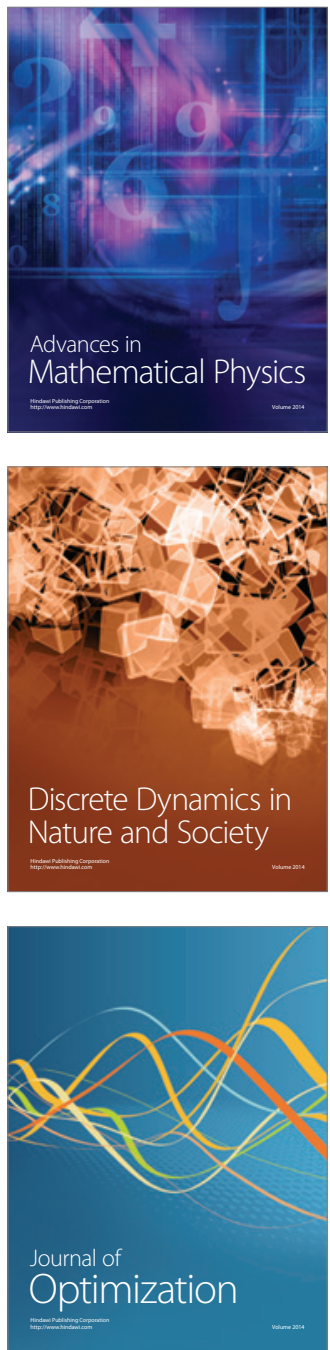